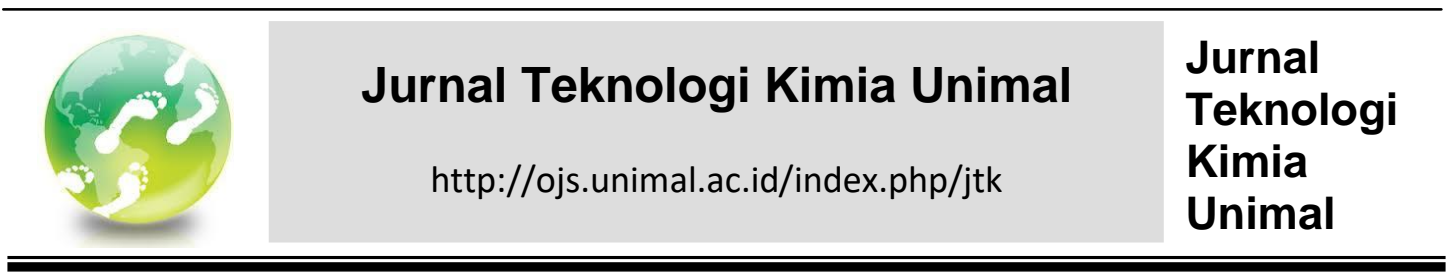

\title{
Aplikasi Parameter Waktu Kontrol PID pada Heat Exchanger dengan Menggunakan Response Surface Methodology (RSM)
}

\author{
Muhammad Ikhsan Nst, Azhari*, Nasrul ZA \\ Jurusan Teknik Kimia, Fakultas Teknik, Universitas Malikussaleh \\ Kampus Utama Cot Teungku Nie Reuleut, Muara Batu, Aceh Utara - 24355 \\ *Korespondensi: azhari@unimal.ac.id
}

\begin{abstract}
Abstrak
Heat exchanger adalah suatu alat yang digunakan untuk memindahkan atau mentransfer energi panas antara suatu permukaan solid dan fluida atau antara partikel padat dan cairan pada suhu yang berbeda dan dalam kontak termal. Tujuan penelitian ini yaitu untuk menentukan nilai Kc, Ti, dan Td terbaik kontrol PID pada Heat exchanger prarancangan pabrik Fenol. Sistem kontrol Proportional-Integral-Derivative (PID) merupakan controller untuk menentukan presisi suatu sistem instrumentasi dengan karakteristik adanya umpan balik pada sistem tersebut (Feed back). Adapun metodologi penelitian ini adalah membuat model steady state Heat Exchanger dari simulasi Pabrik Fenol, kemudian mengubah model steady state menjadi model dynamic, lalu membuat model kontrol PID, setelah itu melakukan tuning terhadap kontrol PID dan melakukan pengujian terhadap kontrol PID dengan set point yaitu $115^{\circ} \mathrm{C}$, dengan melakukan gangguan pada PV. Hasil dari pengaplikasian sistem kontrol PID maka didapatkan rata-rata waktu tercepat dengan nilai $\mathrm{Kc}=8,82, \mathrm{Ti}=2,58 \mathrm{Td}=0$ yaitu 0,38 menit.

Kata Kunci: heat exchanger, PID, present value, set point
\end{abstract}

\begin{abstract}
Abstarct
Heat exchangers are tools used to transferring or transfer heat energy between a solid surface and fluid or inside different particles and in thermal contact. The objective of the study was to determine the optimum values of $\mathrm{Kc}$, Ti and the best Td which to Heat exchangers of factory phenol design. Proportional-IntegralDerivative (PID) is a controller to determine the precision of an instrumentation system with the characteristics of feedback on the system. As the methodology of this research is to create a steady state Heat Exchanger model, then change the steady state model into a dynamic model, so create a PID model control, then tuning the PID control and testing PID controls, by disturbing the set point setting the valid point $115{ }^{\circ} \mathrm{C}$. The result of applying PID control system then got the fastest average time with value $\mathrm{Kc}=8,82, \mathrm{Ti}=2,58, \mathrm{Td}=0$ that is 0,38 minutes. At a temperature of 147.6 air vapor rate of $290.8 \mathrm{Kg} / \mathrm{hr}$; at a temperature of 148.6 found
\end{abstract}


Keywords: $\quad$ heat exchanger, PID, set point, set point

\section{Pendahuluan}

Penukar panas atau heat exchanger adalah suatu alat yang memungkinkan perpindahan panas dan bisa berfungsi sebagai pemanas maupun sebagai pendingin. Biasanya, medium pemanas yang dipakai adalah uap lewat panas (super heated steam) dan air biasa sebagai air pendingin (cooling water). Penukar panas dirancang sebisa mungkin agar perpindahan panas antarfluida dapat berlangsung secara efisien.

Masalah utama dalam perancangan kontrol PID (Proporsional Integral Derivative) adalah tuningnya (penentuan nilai $\mathrm{Kc}, \mathrm{Ti}, \mathrm{Td}$ ). Adapun cara untuk mentuning ketiga parameter tersebut dapat menggunakan Metode Ziegler-Nicolas ataupun Metode Trial And Error. Pada penelitian ini, metode yang digunakan adalah metode kontrol PID secara trial and error hal ini tidak dapat dipungkiri, sampai saat ini kontrol PID (Proporsional Integral Derivative) merupakan satu satunya strategi yang paling banyak diadopsi pada pengontrolan variabel proses di industri. Kepopuleran PID sebagai komponen kontrol proses dilatar belakangi terutam oleh kesederhanaan struktur, serta kemudahan dalam melalukan tuning parameter kontrolnya (Setiawan, 2008).

Penelitian ini bertujuan untuk untuk menentukan nilai $\mathrm{Kc}$, $\mathrm{Ti}$, terbaik kontrol PID temperature pada Heat exchanger pra-rancangan pabrik fenol dengan mendapatkan waktu respon minimum.

\section{Tinjauan Pustaka}

\section{Heat Exchanger Shell and Tube}

Alat penukar panas cangkang dan buluh (Shell and Tube) terdiri atas suatu bundel pipa yang dihubungkan secara paralel dan ditempatkan dalam sebuah pipa mantel (cangkang). Fluida yang satu mengalir di dalam bundel pipa, sedangkan fluida yang lain mengalir di luar pipa pada arah yang sama, berlawanan, atau bersilangan. Kedua ujung pipa tersebut dilas pada penunjang pipa yang menempel 
pada mantel (buffle). Untuk meningkatkan efisiensi pertukaran panas, biasanya pada alat penukar panas cangkang dan buluh dipasang sekat (buffle). Ini bertujuan untuk membuat turbulensi aliran fluida dan menambah waktu tinggal (residence time), namun pemasangan sekat akan memperbesar pressure drop operasi dan menambah beban kerja pompa, sehingga laju alir fluida yang dipertukarkan panasnya harus diatur.

\section{Kontrol Proporsional (P)}

Pengendali jenis P ((Proporsional) ini terdapat hubungan yang sebanding atau proporsional antara keluaran terhadap kesalahan, secara lebih sederhana dapat dikatakan bahwa keluaran pengendali proportional merupakan perkalian antara konstanta propotional dengan masukannya.

\section{Kontrol Proporsional dan Integral (PI)}

Pengontrol PI dikatakan memiliki karakteristik yang sama dalam waktu naik dan overshoot mengecil. Dibandingkan dengan pengendali P, pengendali PI menampilkan hasil tanggapan yang lebih baik dengan mengecilnya overshoot.

\section{Kontrol Proporsional dan Derivative (PD)}

Kontrol PD menghasilkan tanggapan yang lebih stabil dan overshoot lebih berkurang dibandingkan dengan pengendali sebelumnya, namun pengaruh terhadap terjadinya kesalahan-kesalahan masih terlihat.

\section{Kendali PID}

Masalah mendasar sistem kontrol adalah tuning atau penalaan, yaitu menemukan nilai parameter yang tepat agar PV (Process Variable) dapat cepat mengejar harga SP (Set Point). Penambahan kontroler PID akan memperbaiki performansi sistem pengendalian. Pada aksi kontrol $\mathrm{P}$, mempunyai arti bahwa besarnya aksi kontrol sesuai dengan besarnya error dengan faktor pengali tertentu. Kelemahan dari aksi ini adalah terdapat steady state error yaitu output 
mempunyai selisih terdapat set point. Aksi kontrol integral (I) akan menghilangkan steady state error, artinya output sistem akan selalu mengejar set point sedekat mungkin. Aksi kontrol integral sering disebut automatic reset control. Kelemahan aksi kontrol integral adalah terjadinya osilasi sehingga mengurangi kestabilan sistem. Aksi kontrol (D) derivatif sering disebut rate control karena kecepatan perubahan error sebanding dengan sinyal kontrol. Artinya apabila ada perubahan error, maka sinyal kontrol beraksi. Aksi kontrol ini memberikan respon terhadap perubahan sinyal error dan mampu mengoreksinya sebelum error bertambah besar. Aksi kontrol ini mampu mengantisipasi error, mempercepat respon sistem dan meningkatkan stabilitas sistem. Kelemahan dari aksi ini adalah terdapat steady steate error karena error konstan tidak akan menghasilkan sinyal kontrol (sistem yang sudah steady tidak menghasilkan aksi kontrol walaupun jauh dari set point).

Aksi kontrol PID merupakan gabungan aksi kontrol dengan penambahan Proporsional, Integral dan derivatif secara bersamaan, yang akan menghasilkan performansi serta keuntungan gabungan ketiganya. PID mempunyai karakteristik reset kontrol dan rate kontrol yaitu meningkatkan respon dan stabilitas sistem serta mengeliminasi steady state error.

Persamaan kontrol PID dalam bentuk Laplace:

$U(s)=K_{p}\left(E(s)+\frac{1}{T i S} E(s)+T_{D} s E(s)\right)$

\section{Metodologi Penelitian}

Penelitian ini menggunakan Software Aspen Hysys V8.8. Tahapan-tahapan yang perlu dilakukan adalah:

1. Membuat model steady state heat exchanger, flow chart dapat steady state dapat dilihat pada Gambar 1.

2. Mengubah model steady state menjadi mode dynamic heat exchanger,flow chart dapat dilihat pada Gambar 2. 
3. Membuat model kontrol PID dan melakukan tuning Kc, Ti dan Td pada unit heat exchanger. Flow chart dapat dilihat pada Gambar 2 dan Gambar 3.

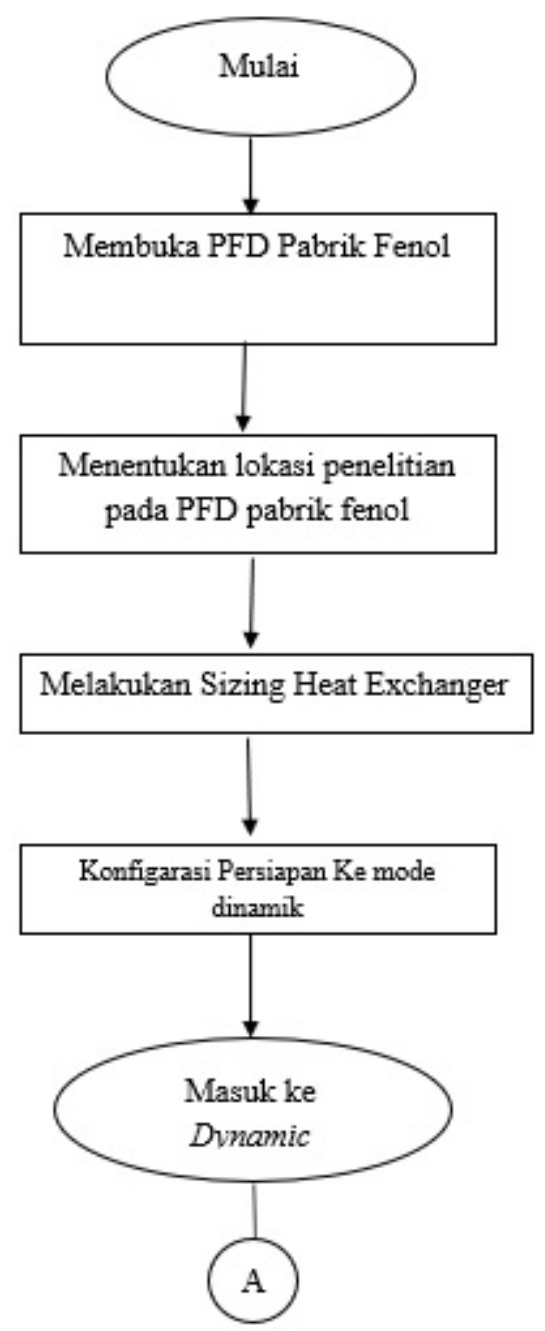

Gambar 1. Bagan Tahapan Penelitian (Steady State)

\section{Hasil dan Pembahasan}

Pada penelitian ini saya melakukan penelitian simulasi pada kontrol PID pada pra rancangan pabrik fenol dari cumene hydroperoxide mengunakan Heat Exchanger sebagai alat yang dikontrol. Jenis Heat Exchanger yang digunakan yaitu 1-2 Shell and Tube. Susunan Tube yang digunakan yaitu tipe Triangular Pitch, dimana susunan triangular memberikan nilai perpindahan panas yang lebih baik bila dibandingkan dengan susunan rotate square dan square karena dengan 
susunan triangular dapat menghasilkan turbulensi yang tinggi Di samping itu letak tube lebih kompak (Dwi, 2012).

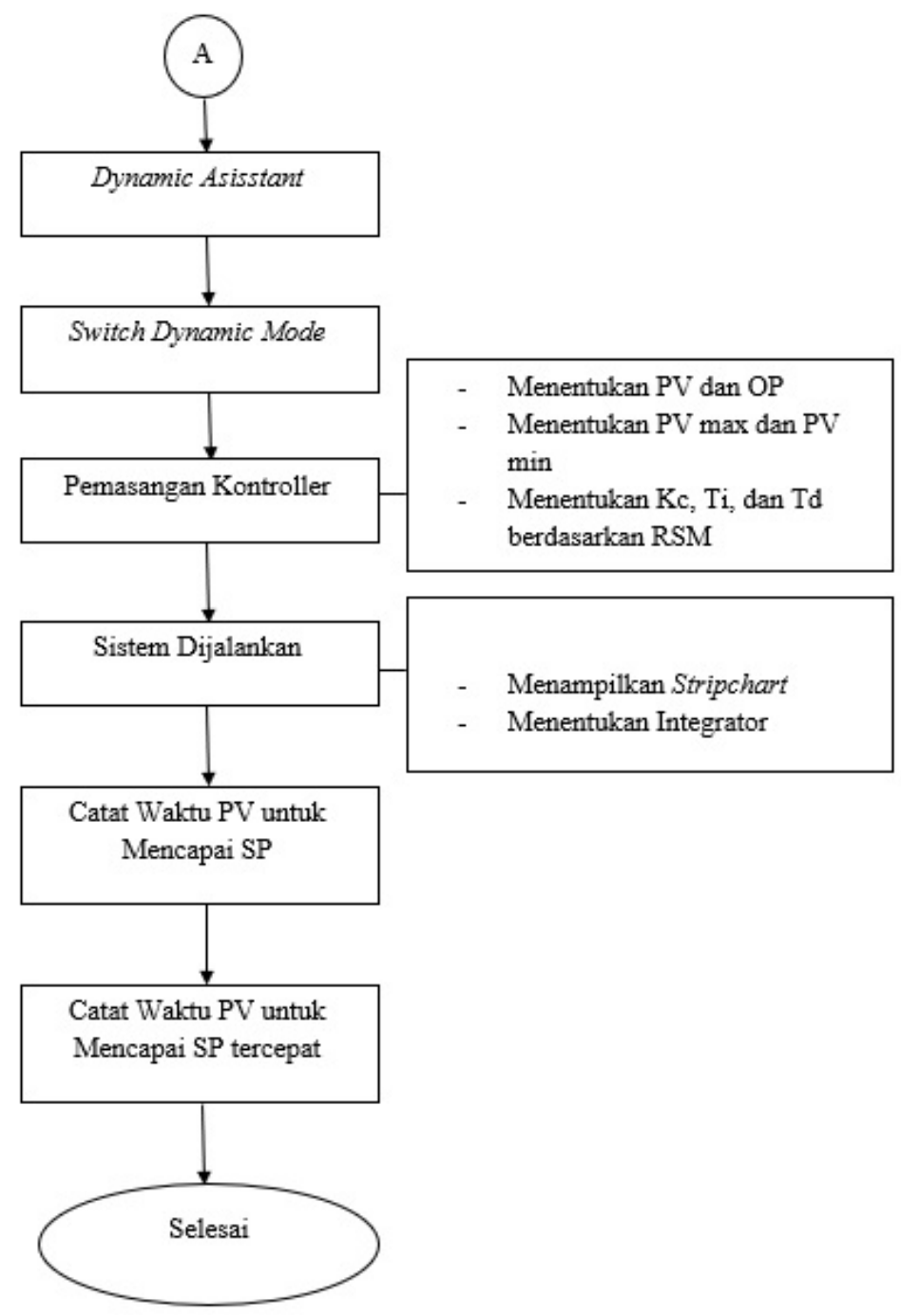

Gambar 2. Bagan Tahapan Penelitian (Dynamic)

Kontroler yang dipakai yaitu kontrol PID untuk mengendalikan suhu keluaran dari reaktor yaitu $438^{\circ} \mathrm{C}$ menjadi $115^{\circ} \mathrm{C}$ pada Heat Exchanger. Shell Side ID $=15$ 1/4 inch, Tube Side Number and Length $=36$ inch, 15'0',. Nilai Pressure drop yang didapatkan dari data Heat Exchanger di pabrik fenol yaitu sekitar 5,14 psi. Nilai Pressure drop yang didapat dari evaluasi design berada dalam Pressure drop standar yaitu berkisar antara 10 psi, sehingga dapat dikatakan design heat exchanger sudah sesuai dengan design standar. 
Penelitian ini bertujuan untuk mengevaluasi kondisi optimum pengoperasian alat penukar panas berdasarkan penyesuaian nilai parameter $\mathrm{Kc}$, $\mathrm{Ti}$, dan $\mathrm{Td}$, dalam upaya untuk mendapatkan waktu respon minimum dengan menggunakan Response Surface Method (RSM). Tujuan digunakannya RSM di penelitian ini adalah untuk mengoptimas rentang data trial $\mathrm{Kc}$, Ti dan $\mathrm{Td}$ agar diperoleh laju alir dan waktu yang optimal.

Tabel 1 Data Hasil Penelitian Menggunaka Hasil Dari RSM

\begin{tabular}{|c|c|c|c|c|}
\hline Run & $\mathrm{Kc}$ & $\mathrm{Ti}$ & Td & Respon (Menit) \\
\hline 1. & 6 & 4 & 0 & 1,63 \\
\hline 2. & 3,17 & 2,58 & 0 & 1,75 \\
\hline 3. & 3,17 & 5,41 & 0 & 4,03 \\
\hline 4. & 6 & 6 & 0 & 2,38 \\
\hline 5. & 6 & 2 & 0 & 0,76 \\
\hline 6. & 8,82 & 2,58 & 0 & 0,38 \\
\hline 7. & 6 & 4 & 0 & 1,63 \\
\hline 8. & 6 & 4 & 0 & 1,63 \\
\hline 9. & 10 & 4 & 0 & 0,91 \\
\hline 10. & 6 & 4 & 0 & 1,63 \\
\hline 11. & 8,82 & 5,41 & 0 & 2,38 \\
\hline 12. & 6 & 4 & 0 & 1,63 \\
\hline 13. & 2 & 4 & 0 & 4,76 \\
\hline
\end{tabular}

Tabel 2 Pengujian kontrol PID yang terbaik dengan nilai $\mathrm{Kc}=8,82 \mathrm{Ti}=\mathbf{2 , 5 8}$ $\mathbf{T d}=\mathbf{0}$

\begin{tabular}{|c|c|c|c|c|}
\hline Temperatur $\left({ }^{\circ} \mathrm{C}\right)$ & $\mathrm{Kc}$ & $\mathrm{Ti}$ & $\mathrm{Td}$ & Waktu (Menit) \\
\hline $115-90$ & \multirow{6}{*}{8,82} & \multirow{6}{*}{2,58} & \multirow{6}{*}{0} & 1,62 \\
\hline $115-100$ & & & & 0,99 \\
\hline $115-110$ & & & & 0,54 \\
\hline $115-120$ & & & & 0,38 \\
\hline $115-125$ & & & & 0,46 \\
\hline $115-130$ & & & & 0,86 \\
\hline \multicolumn{4}{|c|}{ Rata-rata } & 0,808333 \\
\hline
\end{tabular}


Penelitian model kontrol PID ini dilakukan di Heat Exchanger pada simulasi prarancangan pabrik fenol dengan kondisi proses yang bersifat dinamik. Dalam pengujian ini akan dilihat respon dari model kontrol dengan menvariasikan nilai setpoint pada range temperatur $\left(115^{\circ} \mathrm{C}-90^{\circ} \mathrm{C}, 115^{\circ} \mathrm{C}-100^{\circ} \mathrm{C}, 115^{\circ} \mathrm{C}-110^{\circ} \mathrm{C}, 115\right.$ ${ }^{\circ} \mathrm{C}-120^{\circ} \mathrm{C}, 115^{\circ} \mathrm{C}-125^{\circ} \mathrm{C}$ dan $\left.115^{\circ} \mathrm{C}-130^{\circ} \mathrm{C}\right)$.

Tabel 1 Pengujian kontrol PID dengan nilai optimal didapat $\mathrm{Kc}=8,8$, Ti $=2,58 \mathrm{Td}=0$, dimana dengan suhu $90^{\circ} \mathrm{C}$ ke $115^{\circ} \mathrm{C}$ didapat waktu respon 1,62 menit, pada suhu $100^{\circ} \mathrm{C}$ ke $115^{\circ} \mathrm{C}$ didapat waktu respon 0,99 menit, pada suhu 110 ${ }^{\circ} \mathrm{C}$ ke $115^{\circ} \mathrm{C}$ didapat waktu respon 0,54 menit, pada suhu $120^{\circ} \mathrm{C}$ ke $115^{\circ} \mathrm{C}$ didapat waktu respon 0,38 menit, pada suhu $125^{\circ} \mathrm{C}$ ke $115^{\circ} \mathrm{C}$ didapat waktu respon 0,46 menit, pada suhu $130^{\circ} \mathrm{C}$ ke $115^{\circ} \mathrm{C}$ didapat waktu respon 0,86 menit dan didapatkan hasil waktu rata-rata 0,80 menit sedangkan bukaan valve (OP) sebesar 59\%.

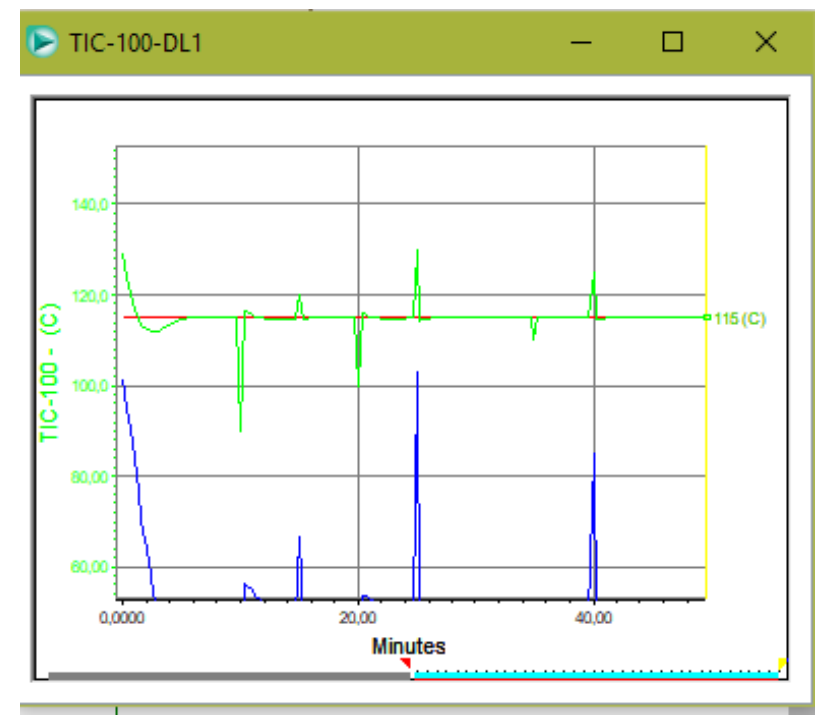

Gambar 3 Grafik hasil pengujian model $\mathrm{PID}$, nilai $\mathrm{Kc}=8,82 \mathrm{Ti}=2,58, \mathrm{Td}=0$

Hasil pengujian model PID pada Gambar 3 dengan menggunakan nilai parameter $\mathrm{Kc}=8,8, \mathrm{Ti}=2,58$ dan $\mathrm{Td}=0$. Pengujian model PID membutuhkan penalaan (tuning) untuk mengatur agar control valve (final control element) merespon error. Masalah penyetelan kontroler proporsional $(\mathrm{Kc})$ adalah sifatnya yang selalu menghasilkan offset. Nilai Kc lebih besar daripada nilai lainnya dikarenakan untuk mengurangi offset. Akan tetapi nilai Kc yang terlalu besar akan 
menyebabkan sistem cenderung tidak stabil (terjadi osilasi) sedangkan apabila nilai Kc terlalu kecil akan menyebabkan penyimpangan variabel proses (PV) proses terlalu besar. Karena Kc menghasilkan offset maka perlu ditambahkan kendali integral yang berfungsi untuk menghilangkan offset.

Nilai Ti yang terlihat pada Gambar 1 bernilai 2,58. Sama halnya dengan Kc, nilai Ti yang terlalu besar akan menyebabkan sistem berosilasi dan apabila terlalu kecil akan mengakibatkan overshoot. Kemudian setelah dilakukan tuning pada Kc dan Ti respon waktu yang didapatkan sangat lambat. Oleh karena itu nilai Td sebesar 0 agar mempercepat tanggapan sekaligus memperkecil overshoot variabel proses dengan memperbaiki respon transien.

Berdasarkan Gambar 3 hasil pengujian model PID terlihat adanya hubungan antara Set Point (SP), Process Variabel (PV) dan bukaan valve (OP). SP adalah nilai variabel proses yang diinginkan. PV adalah besaran yang menyatakan keadaan proses dan OP adalah controller output yang sebelumnya diubah dulu oleh transducer menjadi sinyal pneumatik untuk mengatur bukaan control valve sehingga didapatkan temperature yang diinginkan. Terlihat grafik SP cenderung tetap. Grafik PV bergerak naik dan turun menyamakan nilainya dengan SP. Perubahan naik turunnya PV berpengaruh terhadap persentase sinyal kontrol (OP). Sehingga dari hasil diketahui bahwa dengan nilai $\mathrm{Kc}=8,82 \mathrm{Ti}=$ 2,58 dan $\mathrm{Td}=0$ sebuah sistem pengendalian suhu dapat diterapkan untuk mendapatkan waktu yang paling optimal. Waktu yang optimal dapat memperkecil kemungkinan kecelakaan kerja, kerusakan peralatan, dan memperkecil keragaman kualitas dan produktivitas.

\section{Hasil dengan menggunakan Design Expert Response Surface Methods (RSM)}

Tabel 3 Design Expert Response Surface Methods (RSM)

\begin{tabular}{|c|l|l|c|}
\hline Run & \multicolumn{1}{|c|}{$\begin{array}{c}\text { Faktor 1 } \\
\text { A:Kc }\end{array}$} & \multicolumn{1}{|c|}{$\begin{array}{c}\text { Faktor 2 } \\
\text { B:Ti }\end{array}$} & $\begin{array}{c}\text { Respons 1 } \\
\text { Waktu } \\
\text { (menit) }\end{array}$ \\
\hline 1 & 6 & 4 & 1,63 \\
\hline 2 & 3,17 & 2,58 & 1,75 \\
\hline
\end{tabular}




\begin{tabular}{|l|l|l|l|}
3 & 3,17 & 5,41 & 4,03 \\
\hline 4 & 6 & 6 & 2,38 \\
\hline 5 & 6 & 2 & 0,76 \\
\hline 6 & 8,82 & 2,58 & 0,38 \\
\hline 7 & 6 & 4 & 1,63 \\
\hline 8 & 6 & 4 & 1,63 \\
\hline 9 & 10 & 4 & 0,91 \\
\hline 10 & 6 & 4 & 1,63 \\
\hline 11 & 8,82 & 5,41 & 2,38 \\
\hline 12 & 6 & 4 & 1,63 \\
\hline 13 & 2 & 4 & 4,76 \\
\hline
\end{tabular}

\section{Analisa Respon 1 (waktu)}

Berikut Analisa Varian (ANOVA) untuk respon waktu pada Tabel 4.

Tabel 4 Analisa Varian (ANOVA) untuk Respon Waktu

\begin{tabular}{|c|c|c|c|c|c|c|}
\hline Source & $\begin{array}{c}\text { Sum Of } \\
\text { Square }\end{array}$ & DF & $\begin{array}{c}\text { Mean } \\
\text { Square }\end{array}$ & $\begin{array}{c}\text { F } \\
\text { Value }\end{array}$ & $\begin{array}{c}\text { P-Value } \\
\text { Prob>F }\end{array}$ & Keterangan \\
\hline Model & 16,86664 & 5 & 3,373329 & 19,06567 & 0.0006 & significant \\
\hline A-Kc & 8,95644 & 1 & 8,95644 & 50,62079 & 0.0002 & \\
\hline B-Ti & 5,397298 & 1 & 5,397298 & 30,50492 & 0.0009 & \\
\hline AB & 2,385785 & 1 & 2,385785 & 13,48419 & 0.0079 & \\
\hline $\mathrm{A}^{2}$ & 0,015285 & 1 & 0,015285 & 0,086391 & 0.7773 & \\
\hline $\mathrm{B}^{2}$ & 0,0196 & 1 & 0,0196 & 0,110777 & 0.7490 & \\
\hline Residual & 1,238524 & 7 & 0,176932 & & & \\
\hline Lack of Fit & 1,238524 & 3 & 0,412841 & & & \\
\hline Pure Error & 0 & 4 & 0 & & & \\
\hline Cor Total & 18,10517 & 12 & & & & \\
\hline
\end{tabular}

Tabel 4 di atas menunjukkan ANOVA Respon Steam dengan Design Expert 6.0.8. model dapat dinyatakan memiliki pengaruh yang signifikan jika model memiliki nilai probabilitas $<0,05$. Namun, jika nilai lebih besar dari 0,1 maka model yang ditunjukkan tidak signifikan. Pada Tabel 4.5 diatas menyatakan bahwa hanya persamaan A memiliki nilai probabilitas $<0,05$ dan memiliki pengaruh signifikan yang berarti bahwa ada hubungan antara variabel bebas dengan variabel terikat. 
Tabel 5 Menunjukkan Nilai $R^{2}$

\begin{tabular}{|l|c|c|c|}
\hline Std.Dev. & 0,420633 & $R$-Squared & 0,931593 \\
\hline Mean & 1,961538 & Adj $R$-Squared & 0,88273 \\
\hline C.V.\% & 21,44403 & Pred $R$-Squared & 0,513549 \\
\hline PRESS & 8,807285 & Adeq $R$-Squared & 13,78178 \\
\hline
\end{tabular}

Model dapat dikategorikan sebagai model yang sesuai bila model tersebut memiliki koefisien korelasi R2 > 0,75. Model yang secara statistik dikategorikan cukup baik bila R2 mendekati 1. Dan model dapat diterima bila model tersebut memiliki koefisien korelasi R2 > 0,50.

Sebuah model dapat dikatagorikan sebagai model yang sesuai apabila model tersebut memiliki koefisien korelasi R2 >0,85. Model pada penelitian ini menunjukkan nilai R2 mendekati nilai 1 yaitu 0,931593 .

Berikut ini adalah persamaan coded factor, yaitu:

Waktu $=+3.39165-1.18253 * \mathrm{Kc}+0.87330 * \mathrm{Ti}+0.073203 * \mathrm{Kc} 2-0.023437$ * $\mathrm{Ti} 2-0.017500 * \mathrm{Kc} * \mathrm{Ti}$

\section{Simpulan}

Dari data hasil penelitian dapat diambil beberapa kesimpulan diantaranya, Kesesuaian nilai konstanta-konstanta $\mathrm{Kc}$, Ti, Td dapat mempengaruhi kemampuan dari kontroler untuk merespon gangguan dengan cepat. Waktu rata-rata tercepat dalam merespon gangguan dengan menvariasikan laju alir yaitu dengan nilai tuning parameter $\mathrm{Kc}=3 \mathrm{Ti}=0,01 \mathrm{Td}=0,04$ waktu yang dibutuhkan 0,38 menit. Nilai yang didapat dari R-Squared yaitu R2 $=0,931593$, menunjukkan dapat diterima.

\section{Daftar Pustaka}

Agnihotri, S. P. and Waghmare, L. M. (2016) 'Optimal tuning of PID controller with time delay system using CS and SRMR technique', Journal of Intelligent \& Fuzzy Systems, 31(3), pp. 1287-1297. doi: 10.3233/IFS162195 .

Budiyanto, S. M. R. W. N. E. (2014). Simulasi Kontrol PID untuk Mengatur Putaran Motor AC. Prosiding SNST Ke-5, 23-28. 
Brogan, W.L., Modern Control Theory, Prentice-Hall, Inc., New Yersey, 1985.

Cengel, Y. A. 1997, "Introduction to Thermodynamics and Heat Transfer", New York:McGraw Hill,.

Cooper, 2000. Practical proses control. Texas

Dewhurst, H. M. and Torres, M. P. (2017) 'Systematic analysis of non-structural protein features for the prediction of PTM function potential by artificial neural networks', PLoS ONE, 12(2), pp. 1-18. doi: 10.1371/journal.pone.0172572.

Donapati, Srinivas, 2006, “Autotuning of PID Controllers”, Delhi: Indian Institute of Technology Bombay.

Dwi, Indra Wibawa., Heat Exchanger, Fakultas Teknik, Universitas Lampung, 2012.

Foust, A.A., 1980, "Principles of Unit Operation", 2nd edition, John WileyAnd Sons Inc., New York.

Kern.D.Q., 1983, Process Heat Transfer, McGraw-Hill Book Company, NewYork.

Navigation controller design using fuzzy logic theory for vehicle parallel automatic parking yibing zhao' (2016), 22(2), pp. 1289-1298.

Nguyen, T. H. and Kim, K.-H. (2017) 'Finite Control Set-Model Predictive Control with Modulation to Mitigate Harmonic Component in Output Current for a Grid-Connected Inverter under Distorted Grid Conditions', Energies, 10(7), p. 907. doi: 10.3390/en10070907.

Pakpahan, Sahat, 1988, Kontrol Otomatik Teori dan Penerapan, Jakarta: Penerbit Erlangga.

Setiawan, Iwan. (2008). "Kontrol PID untuk Proses Industri“. Jakarta: PT Elex Media Komputindo.

Setiawan, I. (2008). Kontrol PID untuk Proses Industri Beragam Struktur dan Metode Tuning Praktis.

Shely Dian, 2010. Peralatan Penukar Panas. Surabaya: Surabaya Press

Sitompul, Tunggul M. 1993, Alat Penukar Kalor, edisi 1. Jakarta: PT.Raja Grafindo Persada. 
S. Patankar, 1980. Numerical Heat Transfer and Fluid Flow, Hemisphere, Washington D.C.

Syahruddin, Nasrul. (2006). "Heat Exchanger Introduction”. Balikpapan

T N Luan et.al, "Design of Multi-Loop PID Controllers Based on the generalized IMC-PID Method with Mp Criterion," International Journal of Control, Automation, and Systems, vol. 5, no. 2, 2007, pp. 212-217. 